\title{
The changing face of transient ischaemic attacks
}

\author{
Mettananda K C D ${ }^{1}$, Ranawaka U K ${ }^{1}$ \\ Journal of the Ceylon College of Physicians, 2019, 50, 64-68
}

\begin{abstract}
A transient ischaemic attack (TIA) is a major warning of an impending stroke. The risk of recurrent TIA or stroke is highest during the first 24 hours. $80 \%$ of recurrence risk is reduced with early initiation of effective treatment.
\end{abstract}

Many things have changed regarding TIAs over the last decade. The definition of TIA has changed from a time-based to a tissue-based one. Strategies for investigation and treatment have changed, with specialist evaluation and management recommended for all TIAs within 24 hours of symptom onset. Dedicated TIA clinics have revolutionized the approach to TIA management.

Improving awareness on early recognition and establishing pathways for rapid delivery of optimal care for TIAs will go a long way in minimizing the burden of stroke in Sri Lanka.

Key words: transient ischaemic attacks, stroke, prevention, NICE 2019 guidelines, Sri Lanka

\section{TIAs predict stroke risk}

A transient ischaemic attack (TIA) is not a simple 'mini-stroke', but a major warning sign of an impending stroke that demands urgent attention. About 15-30\% of all ischaemic strokes are preceded by TIAs ${ }^{1-4}$. The estimated recurrent TIA and stroke risk at three months after a TIA is $17.3 \%^{1}$; the risk of stroke is greatest immediately after a TIA, providing only a short window of opportunity for stroke prevention ${ }^{2} .52 \%$ of all strokes during the first 7 days and $42 \%$ of all strokes during the first 30 days following a TIA do occur within the first 24 hours $^{2-5}$. Early and optimal treatment of TIA has been shown to be effective in prevention of recurrent
TIA and stroke. An 80\% reduction of recurrent TIA and stroke risk was reported with the early initiation of existing standard treatments of TIAs and minor strokes (EXPRESS study, 2007) ${ }^{6}$.

\section{TIA: many things have changed}

The definition of TIA has changed

TIAs were traditionally defined as focal neurologic symptoms and/or signs of sudden onset and lasting less than 24 hours, due to transient decrease in blood flow to the brain. However, with significant advances in the understanding of pathophysiology of TIAs and increased availability of advanced neuroimaging techniques, the definition of TIA has changed from a time-based to a tissue-based one. The need for a tissue-based definition was felt with the realization that $30-50 \%$ of classically defined TIAs show brain infarctions on diffusion-weighted MRIs, especially those lasting more than 60 minutes $^{7-9}$. TIA is now defined as a transient episode of neurological dysfunction caused by central nervous system ischaemia without acute infarction ${ }^{9}$. The new definition of TIA, however, is not widely practised as it requires MRI imaging which is not routinely available in many clinical settings.

\section{Evaluation of TIA has changed}

Strategies for investigation and treatment of TIAs vary with the risk of recurrent TIA or stroke following the incident event. Therefore. several scoring systems were developed and updated to predict the short-term recurrent TIA and stroke risk following a TIA $A^{4,10,11}$. The $A B C D 2$ score is one of the most widely used scoring systems ${ }^{11}$. It stratifies patients into three different risk groups; low (<4), moderate (4-5), and high (6-7) risk indicating a 2 -day stroke risk of $1 \%, 4 \%$ and $8 \%$ respectively ${ }^{12}$. However, recent studies have highlighted

\footnotetext{
${ }^{1}$ Faculty of Medicine, University of Kelaniya, Sri Lanka.

Corresponding author: MKCD, e-mail: chamilametta@hotmail.com
}

This is an open-access article distributed under the terms of the Creative Commons Attribution License, which permits unrestricted use, distribution, and reproduction in any medium, provided the original author and source are credited. 
several limitations of the ABCD2 score, especially lack of specificity in detecting recurrent TIA or stroke. A recent meta-analysis has shown that an ABCD2 score of $\geq 4$ has $87 \%$ sensitivity but only $35 \%$ specificity in predicting a recurrent TIA or stroke within first 7 days of a TIA $^{13}$. Several modifications to the ABCD2 score have produced revised scores with improved predictive value, e.g. addition of neuroimaging data on brain infarction (ABCD2I score) ${ }^{14}$, addition of aetiology, and DWI-positivity on MRI (ABCDE $\oplus$ score) ${ }^{15}$. However, these modifications require imaging data which is not freely available especially in developing countries. The National Institute for Clinical Excellence (NICE) of the UK, in its recent (May 2019) revision to the guidelines on assessment and management of TIAs, recommends not to use risk scores to guide management ${ }^{16}$. This is a marked shift from the current practice worldwide and acknowledges the limitations of the risk stratification scores. The NICE recommendations emphasize the importance of considering all TIAs as high risk deserving urgent attention.

\section{Management of TIA has changed}

Recent evidence suggests that urgent assessment and treatment leads to reduction of stroke risk. The patient populations in whom TIAs were managed based on the rapid evaluation and treatment strategies used in the EXPRESS study have reported much lower stroke risks ${ }^{17,18}$. The risk of recurrent stroke at 90 days has been shown to decrease from $12-20 \%$ to $3.7 \%$ within the short span of one decade (from 1997/2003 to $2009 / 2011)^{6,17}$, and this is believed to be due to the implementation of rapid and optimal recurrent stroke or TIA prevention strategies in current practice. Dedicated specialist TIA clinics have been developed in many countries to meet this need for rapid assessment and management of TIAs ${ }^{19-21}$. Specialist evaluation and management of all TIAs within 24 hours of symptom onset is now recommended ${ }^{16}$. This, again, is a change from the existing strategy of referring only high-risk TIAs for evaluation within 24 hours $^{16,22}$.

Early optimal medical treatment of index event is the cornerstone of prevention of recurrent stroke or TIA. Aspirin is the preferred antiplatelet agent, and all patients are recommended immediate treatment with aspirin $300 \mathrm{mg} / \mathrm{d}^{16,22,23}$. The combination of aspirin and clopidogrel is widely used based on findings from some recent studies ${ }^{24-27}$, but the duration of clopidogrel use is unclear. Addition of clopidogrel $75 \mathrm{mg} / \mathrm{d}$ for a short term (21-30 days) is considered better than intermediate term ( $<3$ months), as it gives the same benefit as intermediate term with lower bleeding risk ${ }^{22,28-34}$.
Long term (>3 months) dual antiplatelet therapy with aspirin and clopidogrel is not recommended due to increased risk of major bleeding as well as excessive all-cause mortality ${ }^{28}$. However, it is important to note that the combination of aspirin and clopidogrel is not recommended in the new NICE guidelines, and aspirin is the only recommended antiplatelet agent ${ }^{16}$. Anticoagulation is advocated for those with cardiogenic embolism $^{16,22}$.

Vascular risk factor modification is crucial in stroke prevention following TIA. Blood pressure should be controlled to $<140 / 90 \mathrm{mmHg}$ in all and $<130 / 80 \mathrm{mmHg}$ in patients with diabetes ${ }^{22}$. Intensive lipid-lowering therapy with statins is advised in patients with lowdensity lipoprotein cholesterol (LDL-C) $>100 \mathrm{mg} / \mathrm{dL}^{22}$. Patients should be screened for diabetes mellitus with FBS or hemoglobin A1C and treated accordingly to achieve a FBS of $<126 \mathrm{mg} / \mathrm{dL}$. Lifestyle modification with smoking cessation, healthy diet, exercise and limiting alcohol consumption are essential ${ }^{22}$.

Urgent evaluation is also needed as the aetiology of TIAs is heterogeneous, and the risk of stroke following TIAs differs with the aetiopathology of the index event ${ }^{35}$. Most TIAs result from large artery atherothrombosis (30-40\%) or cardiogenic embolism (15$20 \%)^{36}$, and the risk of early recurrent stroke is considered highest in those with large artery atherothrombosis ${ }^{37}$. Early evaluation, therefore, should include imaging of the extracranial cerebral arterial system (doppler ultrasound, CT or MR angiography) and a search for cardiac sources of embolism (ECG, echocardiogram ${ }^{38,39}$ as priorities in addition to routine blood investigations for risk factors ${ }^{36,40}$. 24-hour or extended Holter monitoring and prolonged cardiac rhythm monitoring (30 days) is recommended where paroxysmal atrial fibrillation is suspected ${ }^{22}$. Early carotid imaging is of critical importance as the benefits of carotid surgery are maximal if surgery is done within 2 weeks of the index event ${ }^{22,41-43}$.

\section{How can we improve TIA management and prevent strokes in Sri Lanka?}

Stroke is a significant burden in Sri Lanka. It is the fourth leading cause of hospital deaths ${ }^{44}$ and is a significant cause of disability. Effective acute treatments such as thrombolysis and mechanical thrombectomy are not freely available in the country, and facilities for rehabilitation of disabled patients are extremely limited. Stroke prevention, therefore, is the most cost-effective strategy for minimizing the stroke 
burden in Sri Lanka ${ }^{45} ; 80 \%$ of early recurrent stroke could be prevented by early treatment of TIA or minor stroke ${ }^{6}$.

Early recognition and initiation of treatment of TIAs is a key component in this strategy. However, awareness of TIA among Sri Lankan first contact doctors has been shown to be inadequate ${ }^{46}$, and there is no data on awareness of TIA among the Sri Lankan public. Education of patients and their relatives regarding symptoms of TIAs and the importance of seeking early medical treatment is important. In addition, updating knowledge of first contact doctors on diagnosis of TIA, emergency treatment and timely referral for specialist opinion is essential. It is important to emphasize that patients and doctors should not be lulled into a false sense of security by the early resolution of symptoms.

Sri Lanka needs to establish dedicated fast track clinics for urgent assessment and management of TIAs, following the benefits demonstrated in other countries ${ }^{6,20,47-49}$. The success of a TIA clinic depends on several factors including fast track access (i.e. appointments made within 24 hours for all patients $)^{48-52}$, assessment by a specialist interested in TIA/stroke ${ }^{53-56}$, rapid access to diagnostic investigations, multidisciplinary care ${ }^{21,57}$ and availability of educational programs ${ }^{57,58}$. Importantly, a TIA clinic is a low-cost effective intervention that can be deployed in any centre in Sri Lanka providing specialist care. Starting island wide stroke/TIA awareness campaigns (such as the FAST campaign) ${ }^{59}$ is a timely need. 'FAST' (unilateral Facial weakness, Arm weakness, Speech difficulty) is an easy way for the public to remember and identify the most common symptoms of a stroke or TIA $^{59}$ and emphasizes the importance of Time in seeking medical attention. Lack of relevant data from Sri Lankan settings is a hindrance to the development of effective preventive strategies, and more research data is needed regarding the incidence, presentations, risk factors and outcome of TIAs in the country.

\section{Conclusion}

Many things have changed regarding TIAs over the last decade: its definition, diagnosis, assessment and management. TIA has now evolved into a condition requiring emergent care, and recent evidence from other countries point to the success of this approach. Developing pathways for such rapid evaluation and treatment of TIAs would go a long way in minimizing the burden of stroke in Sri Lanka.

\section{References}

1. Coull AJL, Rothwell PM. Population based study of early risk of stroke after transient ischaemic attack or minor stroke: implications for public education and organisation of services. British Medical Journal 2004; 328(7435): 326.

2. Rothwell PM, Warlow CP. Timing of TIAs preceding stroke: time window for prevention is very short. Neurology 2005; 64(5): 817-20.

3. Chandratheva A, Mehta Z, Geraghty OC, Marquardt L, Rothwell PM. Population-based study of risk and predictors of stroke in the first few hours after a TIA. Neurology 2009; 72(22): 1941-7.

4. Rothwell PM, Flossmann MF, Lovelock E, Redgrave CE, Warlow JN, Mehta CP. A simple score (ABCD) to identify individuals at high early risk of stroke after transient ischaemic attack. Lancet 2005; 366(9479): 29-36.

5. Johnston SC, Gress DR, Browner WS, Sidney S. Shortterm prognosis after emergency department diagnosis of TIA. Journal of the American Medical Association 2000; 284(22): 2901-6.

6. Rothwell PM, Giles MF, Chandratheva A, et al. Effect of urgent treatment of transient ischaemic attack and minor stroke on early recurrent stroke (EXPRESS study): a prospective population-based sequential comparison. Lancet 2007; 370(9596): 1432-42.

7. Albers GW, Caplan LR, Easton JD, et al. Transient Ischemic Attack-Proposal for a New Definition. New England Journal of Medicine 2002; 347(21): 1713-6.

8. Kidwell CS, Alger JR, Di Salle F, et al. Diffusion MRI in patients with transient ischemic attacks. Stroke 1999; 30(6): 1174-80.

9. Easton JD, Saver JL, Albers GW, et al. Definition and evaluation of transient ischemic attack. Stroke 2009; 40(6): 2276-93.

10. Hankey GJ, Slattery JM, Warlow CP. Transient ischaemic attacks: which patients are at high (and low) risk of serious vascular events? Journal of Neurology, Neurosurgery and Psychiatry 1992; 55(8): 640-52.

11. Johnston SC, Rothwell PM, Nguyen-Huynh MN, et al. Validation and refinement of scores to predict very early stroke risk after transient ischaemic attack. Lancet 2007; 369(9558): 283-92.

12. Giles MF, Rothwell PM. Risk of stroke early after transient ischaemic attack: a systematic review and meta-analysis. Lancet Neurology 2007; 6(12): 1063-72.

13. Wardlaw JM, Brazzelli M, Chappell FM, et al. ABCD2 score and secondary stroke prevention: meta-analysis and effect per 1,000 patients triaged. Neurology 2015; 85(4): 373-80.

14. Giles MF, Albers GW, Amarenco $P$, et al. Addition of brain infarction to the $A B C D 2$ Score (ABCD2I): a collaborative analysis of unpublished data on 4574 patients. Stroke 2010; 41(9): 1907-13. 
15. Engelter ST, Amort M, Jax F, et al. Optimizing the risk estimation after a transient ischaemic attack - the ABCDE plus sign in circle score. European Journal of Neurology 2012; 19(1): 55-61.

16. NICE. Stroke and transient ischaemic attack in over 16s: diagnosis and initial management 2019 [updated] May 2019.

17. Amarenco PL, Philippa C. Labreuche, et al. One-Year Risk of Stroke after Transient Ischemic Attack or Minor Stroke. New England Journal of Medicine 2016; 374(16): 1533-42.

18. Amarenco P, Lavallée PC, Monteiro Tavares L, et al. FiveYear Risk of Stroke after TIA or Minor Ischemic Stroke. New England Journal of Medicine 2018; 378(23): 2182-90.

19. Lavallee P, Amarenco P. TIA clinic: a major advance in management of transient ischemic attacks. Frontiers of Neurology and Neuroscience 2014; 33: 30-40.

20. Lavallee PC, Meseguer E, Abboud H, et al. A transient ischaemic attack clinic with round-the-clock access (SOSTIA): feasibility and effects. The Lancet Neurology 2007; 6(11): 953-60.

21. Krishnan $\mathrm{M}$, Jones $\mathrm{A}, \mathrm{Anjum} \mathrm{T}$, et al. Challenges in reducing TIA clinic waiting times from 9 to 3 days in an acute Welsh hospital. British Medical Journal Open Quality 2018; 7(4): e000237.

22. Kernan Walter N, Ovbiagele B, Black Henry R, et al. Guidelines for the Prevention of Stroke in Patients With Stroke and Transient Ischemic Attack. Stroke 2014; 45(7): 2160-236.

23. Alberts MJ. Pooled RCTs: After ischemic stroke or TIA, aspirin for secondary prevention reduced early recurrence and severity. Annals of Internal Medicine 2016; 165(6): Jc27.

24. Wang $Y$, Pan $Y$, Zhao $X$, et al. Clopidogrel with Aspirin in Acute Minor Stroke or Transient Ischemic Attack (CHANCE) Trial: One-Year Outcomes. Circulation 2015; 132(1): 40-6.

25. Kennedy J, Hill MD, Ryckborst KJ, Eliasziw M, DemchukAM, Buchan AM. Fast assessment of stroke and transient ischaemic attack to prevent early recurrence (FASTER): a randomised controlled pilot trial. The Lancet Neurology 2007; 6(11): 961-9.

26. Liu Y, Fei Z, Wang W, Fang J, Zou M, Cheng G. Efficacy and safety of short-term dual- versus mono-antiplatelet therapy in patients with ischemic stroke or TIA: a meta-analysis of 10 randomized controlled trials. Journal of Neurology 2016; 263(11):2247-59.

27. Zhou X, Tian J, Zhu MZ, He CK. A systematic review and meta-analysis of published randomized controlled trials of combination of clopidogrel and aspirin in transient ischemic attack or minor stroke. Experimental and Therapeutic Medicine 2017; 14(1): 324-32.

28. Rahman H, Khan SU, Nasir F, Hammad T, Meyer MA, Kaluski E. Optimal Duration of Aspirin Plus Clopidogrel After Ischemic Stroke or Transient Ischemic Attack. Stroke 2019; 50(4): 947-53.
29. Prasad K, Siemieniuk R, Hao Q, et al. Dual antiplatelet therapy with aspirin and clopidogrel for acute high risk transient ischaemic attack and minor ischaemic stroke: a clinical practice guideline. British Medical Journal 2018; 363: k5130.

30. Johnston SC, Easton JD, Farrant M, et al. Clopidogrel and Aspirin in Acute Ischemic Stroke and High-Risk TIA. New England Journal of Medicine 2018; 379(3): 215-25.

31. Grotta JC. Antiplatelet Therapy after Ischemic Stroke or TIA. New England Journal of Medicine 2018; 379(3): 291-2.

32. Wang $Y$, Wang $Y$, Zhao $X$, et al. Clopidogrel with Aspirin in Acute Minor Stroke or Transient Ischemic Attack. New England Journal of Medicine 2013; 369(1): 11-9.

33. Stavros K. Kakkos, Ioannis A. Tsolakis. Clopidogrel with Aspirin in Minor Stroke or Transient Ischemic Attack. New England Journal of Medicine 2013; 369(14): 1375-7.

34. Chimowitz MI, Lynn MJ, Derdeyn CP, et al. Stenting versus aggressive medical therapy for intracranial arterial stenosis. New England Journal of Medicine 2011; 365(11): 993-1003.

35. Adams HP, Bendixen BH, Kappelle LJ, et al. Classification of subtype of acute ischemic stroke. Definitions for use in a multicenter clinical trial. TOAST. Trial of Org 10172 in Acute Stroke Treatment. Stroke 1993; 24(1): 35-41.

36. Chung JW, Park SH, Kim N, et al. Trial of ORG 10172 in Acute Stroke Treatment (TOAST) Classification and Vascular Territory of Ischemic Stroke Lesions Diagnosed by Diffusion? Weighted Imaging. Journal of the American Heart Association: Cardiovascular and Cerebrovascular Disease 2014; 3(4): e001119.

37. Lovett JK, Coull AJ, Rothwell PM. Early risk of recurrence by subtype of ischemic stroke in population-based incidence studies. Neurology 2004; 62(4): 569-73.

38. Wilson CA, Tai W, Desai JA, et al. Diagnostic Yield of Echocardiography in Transient Ischemic Attack. Journal of Stroke and Cerebrovascular diseases 2016; 25(5): $1135-40$.

39. Sanna T, Diener HC, Passman RS, et al. Cryptogenic stroke and underlying atrial fibrillation. New England Journal of Medicine 2014; 370(26): 2478-86.

40. Khare S. Risk factors of transient ischemic attack: An overview. Journal of mid-life Health 2016; 7(1): 2-7.

41. Rothwell PM, Eliasziw M, Gutnikov SA, Warlow CP, Barnett $\mathrm{HJ}$. Endarterectomy for symptomatic carotid stenosis in relation to clinical subgroups and timing of surgery. Lancet 2004; 363(9413): 915-24.

42. Mantese VA, Timaran CH, Chiu D, Begg RJ, Brott TG. The Carotid Revascularization Endarterectomy versus Stenting Trial (CREST): stenting versus carotid endarterectomy for carotid disease. Stroke 2010; 41(10 Suppl): S31-4.

43. Brott TG, Hobson RW, Howard G, et al. Stenting versus endarterectomy for treatment of carotid-artery stenosis. The New England Journal of Medicine 2010; 363(1): 11-23. 
44. Medical Statistics Unit $\mathrm{MoH}$, Nutrition and Indigenous Medicine. Annual Health Bulletine-2014, Sri Lanka. Colombo 2016.

45. Ranawaka UK, De Silva, H, Balasuriya, et al. Stroke awareness in a Sri Lankan community Introduction. Journal of the Ceylon College of Physicians 2016; 47(1): 31-5.

46. Mettananda KCD, Kumarasiri J, Rajaguru RDHP, Perera HAGM, Wijerathne PMNM. Awareness on diagnosis and management of transient ischemic attacks (TIA) among Sri Lankan doctors. Sri Lanka Medical Association 129th Anniversary International Medical Congress, Sri Lanka, 2016; Colombo 2016.

47. Hosier GW, Phillips SJ, Doucette SP, Magee KD, Gubitz GJ. Transient ischemic attack: management in the emergency department and impact of an outpatient neurovascular clinic. Canadian Journal of Emergency Medicine 2016; 18(5): 331-9.

48. Majidi S, Leon Guerrero CR, Burger KM, Rothrock JF. Inpatient versus Outpatient Management of TIA or Minor Stroke: Clinical Outcome. Journal of Vascular and Interventional Neurology 2017; 9(4): 49-53.

49. Wasserman J, Perry J, Dowlatshahi D, et al. Stratified, urgent care for transient ischemic attack results in low stroke rates. Stroke 2010; 41(11): 2601-5.

50. National Institute of Clinical Studies. Emergency department stroke and transient ischemic attack care bundle: information and implementation package. Melbourne: National Health and Medical Research Council; 2009. Available from: https:// www.nhmrc.gov.au/about-us/publications/emergencydepartment-stroke-and-transient-ischaemic-attack-carebundle.
51. Jarhult SJ, Howell ML, Barnaure-Nachbar I, et al. Implementation of a Rapid, Protocol-based TIA Management Pathway. The Western Journal of Emergency Medicine 2018; 19(2): 216-23.

52. National Collaborating Centre for Chronic Conditions. Stroke: National Clinical Guideline for Diagnosis and Initial Management of Acute Stroke and Transient Ischaemic Attack (TIA). National Institute for Health and Clinical Excellence: Guidance. London: Royal College of Physicians (UK); 2008.

53. Castle JM, Lee M, Caulfield K, et al. Agreement regarding diagnosis of transient ischemic attack fairly low among stroke-trained neurologists. Stroke 2010; 41(7): 1367-70.

54. Kraaijeveld CL, Gijn VJ, Schouten HJ, Staal A. Interobserver agreement for the diagnosis of transient ischemic attacks. Stroke 1984; 15(4): 723-5.

55. Ranta A, Alderazi YJ. The importance of specialized stroke care for patients with TIA. Neurology 2016; 86(22): 2030-1.

56. Sacco RL, Rundek T. The Value of Urgent Specialized Care for TIA and Minor Stroke. New England Journal of Medicine 2016; 374(16): 1577-9.

57. Bergman D. Preventing recurrent cerebrovascular events in patients with stroke or transient ischemic attack: the current data. Journal of the American Academy of Nurse Practitioners 2011; 23(12): 659-66.

58. Gomez CR, Schneck MJ, Biller J. Recent advances in the management of transient ischemic attacks. F1000 Research 2017; 6: 1893.

59. American Stroke Association. Act FAST: [updated 2017; cited 2020 2020.04.11]. Available from: https://www.stroke.org/ en/about-stroke/stroke-symptoms. 